\title{
Comparative Analysis of Microwave and Electric Arc as a New Method in Weed Control
}

\author{
Hasan Sahin
}

\begin{abstract}
The increase in the demand for organic production and the adverse effects of chemicals used in agriculture have brought non-chemical weed control methods to the fore. Among these methods, the most studied ones are microwave and electric arc methods. It has been determined in studies that microwaves and electric current, when applied at the correct power level and for sufficient time, biologically inactivate weeds, all kinds of unwanted plants and seeds. In this study, the mortality rates caused by microwave energy and electric current (arc) methods in some plants applied under laboratory conditions were compared. Studies have shown that the effectiveness of microwave and electric arc methods depends on the selected current, voltage, power level and exposure time. It is thought that the electric arc method is easier and more economical in terms of application in the field than the microwave method. Another purpose of this study is to remind agricultural policy makers and decision makers of the importance of alternative weed control methods and to ensure that they make policies in this direction.
\end{abstract}

Index Terms - non-chemical weed control, environmentally friendly, weed management, agro-chemicals.

\section{INTRODUCTION}

Agricultural chemicals are mostly preferred in the control of unwanted plants and seeds in agricultural production. Chemicals used in weed control affect the physiological development of weeds and aim to minimize or eliminate economic loss. These types of agricultural chemicals are widely used in non-agricultural areas to control weeds. However, in scientific studies, it has been determined that herbicides detected in drinking water can only be separated from water by ozone treatment method. As the damages of chemicals used in weed control are understood and environmental sensitivity increases, non-chemical weed control methods gain more importance. To abandon chemical control methods and to include completely natural plant production, that is, to move towards organic agriculture, appears to be a highly desired situation by the society. However, many manufacturers very quickly accept the use of chemicals due to the easy accessibility and economy of the application.

However, due to the understanding of the damages, these chemicals cause to the soil, water and natural life, there is an increase in scientific studies on non-chemical control methods such as microwave and electric arc. The most prominent of these methods is the electric current method and the methods of using microwaves. Both methods use electrical energy. In the microwave and electric arc method,

Submitted on February 7, 2021.

Published on February 19, 2021.

H. Sahin, Department of Agricultural Machinery, Harran University, Turkey.

(e-mail: hsahin@harran.edu.tr) no chemical residues are formed in the soil and agricultural products after the application. In weed control with microwave, almost all of the weeds and seeds can be neutralized when microwaved with sufficient power and time is applied [1], [2]. The interaction of microwaves and materials with which electric current is applied is closely related to the dielectric properties of materials. Electromagnetic properties such as electric field permittivity, conduction, reflection, dispersion and refraction are expressed depending on the dielectric properties of materials. The small amount of water or moisture contained in the material significantly affects the dielectric properties of the material. How much material is exposed to microwaves heats depends on the dielectric properties of the material, $\varepsilon$ (permittivity), $\varepsilon^{\prime}$ (dielectric constant) and $\varepsilon^{\prime \prime}$ (dielectric loss factor). The unit is $(\mathrm{F} / \mathrm{m})$ Farad/meter.

For this reason, knowing the dielectric properties of biological materials to be exposed to microwave is important in terms of energy efficiency. It is also known that the low-frequency dielectric properties of biological tissues differ according to the tissue [3].

Cell death in living organisms such as plant cells exposed to microwave occurs due to the microwave electric field together with the thermal effect of microwave [4]. In weed control studies with microwave, although an increase in seed germination was observed in short-term microwave applications, it was observed that there was a restriction in seed germination in longer-term applications [5], [6]. Some of the microwaves (thermal losses) produced during weed control applications with microwave energy leaks to the outside environment, increasing the energy cost of the microwave method and weakening its competitiveness with chemical methods [7], [8].

Weed control with an electric arc is one of the nonchemical alternative methods. However, although it is not a subject that has been studied as much as microwave applications, some studies have been carried out recently. In such studies, it is aimed to end the vital activity of the plant as a result of the flow of electric current through the weed. The electrical discharge system (EDS) is also used in the destruction of weeds that grow more than the cultivated plant. In this method, an electrical voltage is applied by increasing it with the help of a transformer. In EDS, when the metal electrode contacts the foreign weed, the electric current completes its circuit through the soil and tries to vaporize the liquid in the tissue by spreading the electrical energy to the plant tissues. In this way, the life of the foreign plant is tried to be restricted. [9] conducted weed control experiments with the electric arc they made.

This setup was used by supplying an electric current to weeds with an electrically conductive rod connected to a high voltage electrical source. 
A sustainable and long-term strategy is required to minimize weeds and maximize crop yield [10]. The widespread use of herbicides in agricultural weed control has caused weeds to develop resistance against some herbicides. This has led to an increased interest in nonchemical weed control methods. Alternative control methods, which determine the most appropriate method to be followed for commercial development, have not yet reached the desired technological level due to a lack of accurate and fair comparison [11]. Developments in detection, vision, and computational efficiency related to the defense industry, automotive, health, and safety industry have also led to the development of weed control techniques. These technologies create an opportunity for site-specific weed management (SSWM) in large-scale agricultural production with individual detection of weeds followed by rapid and accurate response [12]. SSWM control methods also allow an accurate comparison of nonchemical weed control methods. Developments in robotics and artificial intelligence are also expected to be potential tools in an IWM (integrated weed management) approach, and these new technologies can support ecological solutions.

\section{MATERIAL AND METHOD}

A vertical type of multi-electrode tunnel has been used to apply the electric arc method under laboratory conditions. The electrode tunnel consists of two $40 \times 50 \mathrm{~cm}$ copper plates consisting of 900 pieces of $1.45 \mathrm{~mm}$ diameter and $4 \mathrm{~cm}$ long vertically mounted copper electrodes (Fig. 1). An electrical circuit was formed by connecting the positive (+) end of the voltage regulator to one of the copper plates and the negative (-) end to the other. The designed electrical circuit was fed with a 0-300 volt stepped power supply. The results were observed by exposing the plants germinated under laboratory conditions to different levels of electric current. Mortality rates of plants exposed to electric current were determined by a TRIMBLE GreenSeeker NDVI (Normalized Difference Vegetation Index) device. The 1week-old germinated plants were exposed to 110, 220 and 300 volts AC with the vertical type multi-electrode method for 100 seconds in triplicate. With the plants passing through the tunnel with the help of a moving conveyor belt, the maximum contact of the plants to approximately 900 vertical copper electrodes were achieved. The rate of plants affected by the electric current was determined by calculating the difference between $\mathrm{NDVI}_{2}$ and $\mathrm{NDVI}_{1}$ values.

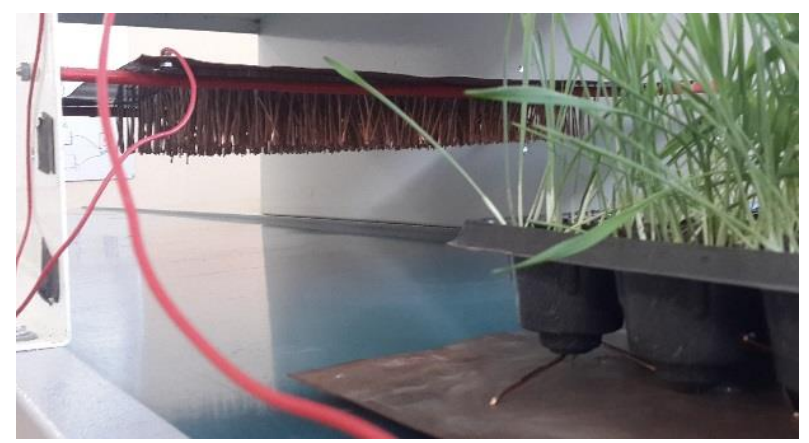

Fig. 1. Vertical type multi-electrode (+), copperplate (-).
The plants germinated under laboratory conditions were exposed to microwave in a speed-controlled tunnel with 4 magnets, each of 700 watts, with a conveyor belt (Fig. 2). The movement of the tractor in the field was tried to be simulated with a speed-controlled conveyor belt. Mortality rates were determined by scanning the plants exposed to the microwave at a different time and power levels with the NDVI device.

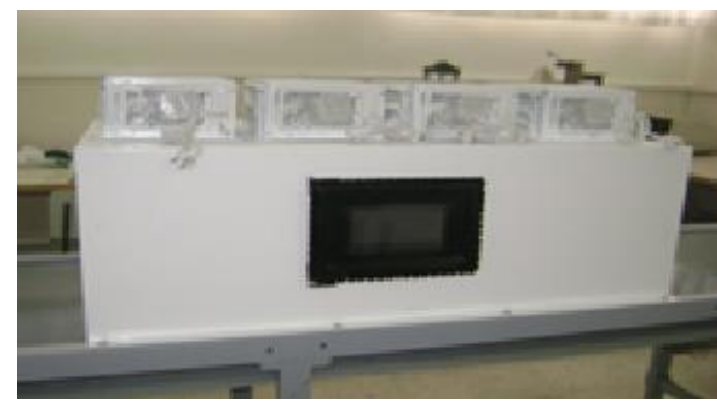

Fig. 2. Speed controlled conveyor belt and microwave tunnel.

In calculating the sample size of the study, the Power (Power of Test) for each variable was determined by taking at least 0.80 and Type 1 Error 0.05 . Whether the continuous variables in the study were normally distributed or not was checked with Shapiro-Wilk $(\mathrm{n}<50)$ and nonparametric tests were applied because the variables were not distributed normally. Descriptive statistics for continuous variables in our study; Median, Average, Standard Deviation, Minimum and Maximum; expressed as. Mann-Whitney U test was used for comparisons. Statistical significance level $(\alpha)$ was taken as $5 \%$ in calculations and statistical software was used for calculations.

\section{RESUlTS AND DISCUSSION}

Mortality rates between $30 \%$ and $100 \%$ occurred in plants exposed to microwave at $120 \mathrm{~s}$ duration and 1400, 2100 and 2800 watt power levels (Table 1). However, an increase in the germination rate was observed in the Barley(Hordeum vulgare) after 1 week at 1400 watt power level. In the control groups, an increase in germination was observed between $6 \%$ and $8 \%$, Fig. 1, [1], [13]-[15].

In the electric arc method, the results obtained by using vertical type electrodes at different duration and voltage levels are as follows. An increase of approximately $4.20 \%$ to $5.90 \%$ was observed in the germination rates of 110 volt Cress (Lepidium sativum) and Barley (Hordeum vulgare) recurrence applied with the vertical type multi-electrode method. Mortality rates of $17.98 \%$ to $92.55 \%$ were obtained at 220 and 300-volt levels depending on the plant types (Table 2). There is an increase of approximately $6 \%$ in the germination rate of the control group Figure 2. Results were calculated by taking the difference between $\mathrm{NDVI}_{1}$ (measured from 1 week old germinated plants) and $\mathrm{NDVI}_{2}$ Fig. 3 and Fig. 4, (measured 1 week after the plants were exposed to electric current). Similar results were obtained, the increase in germination rates in 110 volt repeats is an approximately $5 \%$ net germination increase compared to the $7 \%$ increase in the control group germination rate. More germination was observed in cress and arugula seeds in short-term microwave applications compared to control 
group that not exposed to microwave. At 220 and 300 volt levels, respectively; Mortality rates of $12 \%$ and approximately $17 \%$ were obtained". And also, in the horizontal type single electrode method, approximately $2 \%$ increase in germination rates was observed in 110 volt repeats. Similar studies have also investigated the effects of microwave energy on plants, seeds and soil [16]-[18]. At 220 and 300 volt levels, respectively; Mortality rates of $8 \%$ and approximately $11 \%$ were achieved. There is an increase of approximately $5 \%$ in the germination rate of the control group. When looking at the comparison of "Mortality Rates" according to "Electrode Method and Voltage Value"; A statistically significant difference was observed between "110 Volt Voltage" and "Mortality Rates in Electrode Methods" ( $\mathrm{p}<0.05)$.

In other words, the level of "mortality rates" was affected by the "being a multiple or single electrode method". Mortality rates were higher in the multiple electrode method compared to the single method (17.33\%).

TABLE 1: MORTALITY RATES OCCURRED IN PLANTS EXPOSED TO MICROWAVES

\begin{tabular}{cccc}
\multicolumn{4}{c}{ MICROWAVES } \\
\cline { 2 - 4 } Mortality rates (\%) & 1400 & 2100 & 2800 \\
\hline Cress (Lepidium sativum) & -3.2 & 60.18 & 68.76 \\
Charlock (Sinapis arvensis) & 37.32 & 97.01 & 98.56 \\
Wild oats (Avena sativa) & 90.41 & 96.50 & 97.63 \\
Barley (Hordeum vulgare) & 30.16 & 60.23 & 70.33 \\
\hline
\end{tabular}

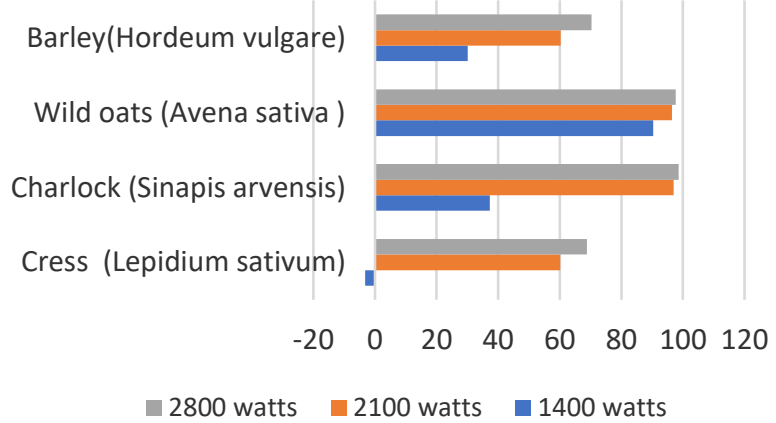

Fig. 3. Mortality rates occurred in plants exposed to microwaves (\%).

TABLE 2: MORTALITY RATES OCCURRED IN PLANTS EXPOSED TO ELECTRIC ARC

\begin{tabular}{lccc}
\multicolumn{4}{c}{ ELECTRIC ARC } \\
\hline \multirow{2}{*}{ Mortality rates (\%) } & \multicolumn{3}{c}{ Electric Arc (volts) } \\
\cline { 2 - 4 } & $\mathbf{- 4 . 2 0}$ & 420 & 300 \\
\hline Cress (Lepidium sativum) & 8.23 & 85.74 & 58.10 \\
Charlock (Sinapis arvensis) & 2.56 & 38.12 & 73.55 \\
Wild oats (Avena sativa) & $\mathbf{5 . 9 0}$ & 17.98 & 25.61 \\
Barley (Hordeum vulgare) & & & \\
\hline
\end{tabular}

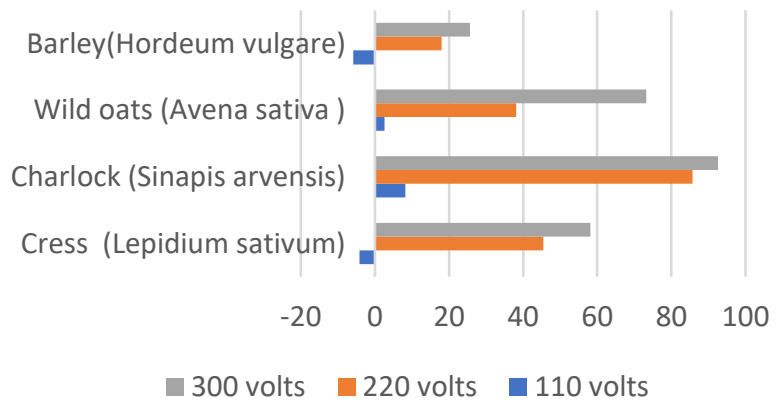

Fig. 4. Mortality rates occurred in plants exposed to electric arc (\%).

\section{CONCLUSION}

In the vertical type of multi-electrode method, $4 \%$ increase in germination rates in 110 -volt repeats was recorded in barley and 5\% in cress. When compared to the $6 \%$ increase in the germination rate of the control group, there is a significant increase in germination. Similar results were obtained in weed control studies with the microwave method. In short-term microwave applications, more germination was observed in Cress (Lepidium sativum) and Barley (Hordeum vulgare) seeds compared to the control group. When using the multi-electrode method, a statistically significant difference was found between the voltage-mortality rates $(\mathrm{p}<0.05)$. A statistically significant difference was found between the "Mortality Rates" observed according to the "Voltage Value" ( $p<0.05)$. The highest mortality rates occurred at 300 volts, 220 volts and 110 volts, respectively. In microwave applications, the highest mortality rates were obtained at 2800 watts. Mortality rates increase significantly as the exposure of plants to electric current and microwave increases. A statistically significant positive correlation was observed between mortality rates and electric current $(p<0.05)$. It can be said that mortality rates increase as the electric current and microwave output power increase. Besides, it is important to correctly determine the energy level and application time to be applied. It should not be forgotten that low voltage applications to be made have the potential to increase germination in weeds. As can be seen from the results, whether it is plants exposed to microwave or plants applied electric current, successful results have been obtained in both methods if they are applied with sufficient power levels and durations. However, although it is said that there is an economic obstacle in the widespread use of these methods, it should be accepted that these and similar environmental methods are always economical when it comes to environment and human health. Because nothing is more valuable than human life.

\section{REFERENCES}

[1] Sahin, H. (2014). Effects of microwaves on the germination of weed seeds. Journal of Biosystems Engineering, 39(4), 304-309.

[2] Sahin, H. (2020). Investigating the effect of single and multiple electrodes on mortality ratio in electric current weed control method with NDVI technique. Journal of the Faculty of Engineering and Architecture of Gazi University, 35(4), 1973-1984.

[3] Kuang, W., Nelson, S.O., 1998. Low-frequency properties of biological tissues: A review with some new insights. American Society of Agricultural Engineers, vol.41(1): 173-184.

[4] Banik, S., Bandyopadhyay, S. And Ganguly, S., 2003. Bioeffects of microwave-a brief review. Bioresource Technology 87 (2003) 155159.

[5] Bebawi, E.F., Cooper, A.F., Brodie, G.I. et al., "Effect of microwave radiation on seed mortality of rubber wine, parthenium and bellyache bush", Plant Protection Quarterly vol.26, no.4, pp.136-142, 2007.

[6] Sahin, H., \& Yalınkılıc, M. (2017). Using Electric Current as a Weed Control Method. European Journal of Engineering Research and Science, 2(6), 59-64.

[7] Brodie G., Ryan, C. And Lancaster, C., 2012. Microwave Technologies as Part of Integrated Weed Management Strategy: A Review. International Journal of Agronomy volume 2012. 636905.

[8] Sahin, H., \& Saglam, R. (2015). A Research About Microwave Effects on The Weed Plants. Journal of Agricultural and Biological Science,

[9] Pluenneke, R. H., \& Dykes, W. G. (1975). Method and Apparatus For Using Electrical Current to Destroy Grasses and Weeds.

[10] Brand, J., Yaduraju, N. T., Shivakumar, B. G., \& Murray, L. (2007) 
Weed management. Lentil, 159-172.

[11] Coleman, G. R., Stead, A., Rigter, M. P., Xu, Z., Johnson, D., Brooker, G. M., \& Walsh, M. J. (2019). Using energy requirements to compare the suitability of alternative methods for broadcast and sitespecific weed control. Weed Technology, 1-18.

[12] Bakker, T., Bontsema, J., \& Müller, J. (2010). Systematic design of an autonomous platform for robotic weeding. Journal of Terramechanics, 47(2), 63-73.

[13] Davis, F., Wayland, J., Merkle, M., 1971. Ultrahigh-Frequency Electromagnetic Fields for Weed Control: Phytotoxicity And Selectivity. Science, 173, 535-537.

[14] Nelson, S., O., 1996. A review and assessment of microwave energy for soil treatment to control pests. Transactions of the ASAE, 39(1), 281-289.

[15] Rana, A., \& Derr, J. F. (2018). Responses of Ten Weed Species to Microwave Radiation Exposure as Affected by Plant Size. Journal of Environmental Horticulture, 36(1), 14-20.

[16] De Wilde, M., Buisson, E., Yavercovski, N., Willm, L., Bieder, L., \& Mesléard, F. (2017). Using microwave soil heating to inhibit invasive species seed germination. Invasive Plant Science and Management, 10(3), 262-270.

[17] Kafarski, Marcin, et al. Evaluation of apple maturity with two types of dielectric probes. Sensors, 2018, 18.1: 121.

[18] Taheri, S., Brodie, G., Jacob, M. V., \& Antunes, E. (2018). Dielectric Properties of Chickpea, Red and Green Lentil in The Microwave Frequency Range as a Function of Temperature and Moisture Content. Journal of Microwave Power and Electromagnetic Energy, $1-17$. 